\title{
openheart Feasibility and outcomes of combined transcatheter aortic valve replacement with other structural heart interventions in a single session: a matched cohort study
}

\author{
Ahmed A Khattab, ${ }^{1}$ Steffen Gloekler, ${ }^{1}$ Beate Sprecher, ${ }^{1}$ Samera Shakir, ${ }^{1}$ \\ Ênio Guerios, ${ }^{2}$ Stefan Stortecky, ${ }^{1}$ Crochan J O'Sullivan, ${ }^{1}$ Fabian Nietlispach, ${ }^{3}$ \\ Aris Moschovitis, ${ }^{1}$ Thomas Pilgrim, ${ }^{1}$ Lutz Buellesfeld, ${ }^{1}$ Peter Wenaweser, ${ }^{1}$ \\ Stephan Windecker, ${ }^{1}$ Bernhard Meier ${ }^{1}$
}

To cite: Khattab AA,

Gloekler S, Sprecher B, et al. Feasibility and outcomes of combined transcatheter aortic valve replacement with other structural heart interventions in a single session: a matched

cohort study. Open Heart 2014;: : e000014. doi:10.1136/openhrt-2013000014

AAK and SG contributed equally.

Received 5 December 2013 Revised 8 May 2014 Accepted 28 May 2014

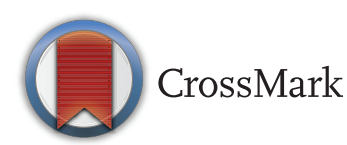

${ }^{1}$ Cardiology, Cardiovascular Department, Bern University Hospital, Bern, Switzerland ${ }^{2}$ Centro de Cardiopatias Congênitas e Estruturais do Paraná, Curitiba, Paraná, Brazil

${ }^{3}$ Department of Cardiology, Zurich University Hospital, Zürich, Switzerland

Correspondence to Professor Bernhard Meier; bernhard.meier@insel.ch

\section{ABSTRACT}

Background: Concurrent cardiac diseases are frequent among elderly patients and invite simultaneous treatment to ensure an overall favourable patient outcome.

Aim: To investigate the feasibility of combined singlesession percutaneous cardiac interventions in the era of transcatheter aortic valve implantation (TAVI).

Methods: This prospective, case-control study included 10 consecutive patients treated with TAVI, left atrial appendage occlusion and percutaneous coronary interventions. Some in addition had patent foramen ovale or atrial septal defect closure in the same session. The patients were matched in a 1:10 manner with TAVI-only cases treated within the same time period at the same institution regarding their baseline factors. The outcome was validated according to the Valve Academic Research Consortium (VARC) criteria.

Results: Procedural time $(126 \pm 42$ vs $83 \pm 40 \mathrm{~min}$, $p=0.0016)$, radiation time $(34 \pm 8$ vs $22 \pm 12 \mathrm{~min}$, $p=0.0001)$ and contrast dye $(397 \pm 89$ vs $250 \pm 105 \mathrm{~mL}$, $p<0.0001$ ) were higher in the combined intervention group than in the TAVI-only group. Despite these drawbacks, no difference in the VARC endpoints was evident during the in-hospital period and after 30 days (VARC combined safety endpoint $32 \%$ for TAVI only and $20 \%$ for combined intervention, $p=1.0$ ).

Conclusions: Transcatheter treatment of combined cardiac diseases is feasible even in a single session in a high-volume centre with experienced operators.

\section{INTRODUCTION}

Percutaneous cardiac interventions, by their less invasive nature, enhance patient comfort, accelerate recovery time and shorten hospitalisation duration. They have proven to be a valid alternative to open heart surgery for different patient and disease subsets. This becomes particularly true among patients with coexisting cardiac diseases necessitating complex combined surgical management which puts them at an additional operative risk. ${ }^{1}{ }^{2}$ With the introduction of transcatheter aortic valve implantation (TAVI), a long neglected population of surgically high-risk and inoperable patients gained access to effective treatment for aortic valve stenosis. ${ }^{3}$ Frequently, however, these elderly patients have concurrent coronary artery disease and/or atrial fibrillation, which are both associated with an independent adverse prognosis. ${ }^{4-6}$ The management of these patients should therefore cover concurrent heart diseases to ensure an overall favourable outcome after TAVI. ${ }^{7}$ Staged or simultaneous percutaneous coronary interventions (PCI) and TAVI have been shown to be safe and feasible in different series. ${ }^{8}{ }^{9} \mathrm{We}$ recently described a successful first case of simultaneous TAVI, PCI and percutaneous device closure of the left atrial appendage (LAA). ${ }^{10}$ LAA occlusion has been demonstrated to be at least equally effective to longterm warfarin therapy in preventing systemic embolism among atrial fibrillation patients ${ }^{11}$ and is commonly used as a substitute for anticoagulation among selected patients not suitable for chronic anticoagulation. ${ }^{12}$ On the other hand, patent foramen ovale (PFO) and atrial septal defects (ASD) are a documented source for systemic emboli ${ }^{13}$ and their percutaneous closure is feasible and effective in reducing paradoxical embolism. ${ }^{14-17}$ We sought to investigate the feasibility of simultaneous cardiac interventions 
Figure 1 Representative course of action in case 2 .

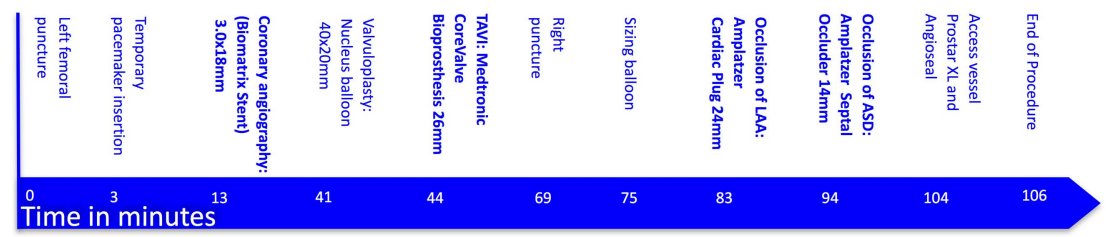

including TAVI, PCI and LAA occlusion with or without $\mathrm{PFO} / \mathrm{ASD}$ closure in an elderly comorbid population.

\section{METHODS \\ Patient population and justification of combined procedures}

Ten consecutive cases were selected from a cohort of 400 patients with severe aortic stenosis allocated to TAVI by the decision of the heart team at the Swiss Cardiovascular Center of the Bern University Hospital between 2009 and 2012. Data were entered into a prospective registry and analysed according to the criteria of the Valve Academic Research Consortium (VARC). ${ }^{18}$ Patient characteristics were compared with a pool of 100 case-control patients to match every patient with a combined intervention to a control according to the Society of Thoracic Surgeons (STS) score. Given the prospective cohort study character, there were no formal exclusion criteria. The Bern TAVI registry is part of the Swiss TAVI registry and has been approved by the local and national ethics committees. The Bern registry for LAA occlusion is also approved by the local ethics committee. For each of the combined interventions, dedicated forms listing potential adverse events, that is, the risk of the respective procedure, were provided. With regard to the risk/ benefit ratio of combined versus staged interventions and especially under the aspect of avoiding several

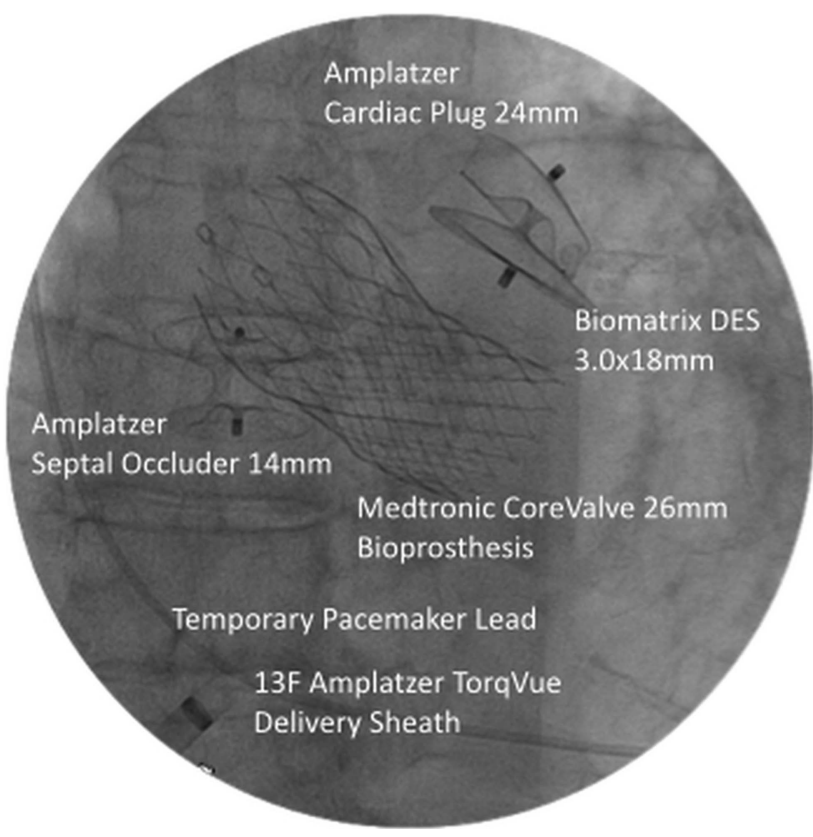

Figure 2 End result in case 2. hospitalisations and general anaesthesia, the combined approach was deemed patient friendly without increasing complications and therefore recommended to the selected patients of this study.

\section{Data acquisition}

Demographic and clinical characteristics, procedural data, adverse events and outcome data of in-hospital and follow-up periods were systematically collected. After 1 and 3-4 months, a standardised follow-up examination was performed. After 3-4 months, in addition to clinical and neurological examination, a transesophageal echocardiography (TEE) was performed to ensure correct seating and freedom of relevant thrombi of the LAA closure device. All events underwent adjudication by a team of an independent cardiac surgeon and an independent interventional cardiologist. Outcome is reported according to the VARC criteria.

\section{Combined interventions}

Beforehand, coronary angiography with invasive haemodynamic assessment, CT angiography (CTA) and TEE for aortic root assessment and exclusion of LAA thrombi were performed. Three of the 10 cases were transmitted live to international interventional courses. If indicated by angiographic stenosis degree, PCI was performed first by transfemoral access with 5 or $6 \mathrm{Fr}$ guiding catheters and exclusively using drug-eluting stents (DES), which was the case in 6 of the 10 combined patients. Two did not suffer from CAD and in two, the CAD was treated earlier in a separate procedure. Next, TAVI was performed under mild sedoanalgaesia and inguinal local anaesthesia only via transfemoral access. A single or both femoral arteries were accessed and a suture-based vascular closure device preinstalled on the respective side of access for TAVI. Aortic stenosis was crossed using an Amplatzer left diagnostic catheter and a straight tipped wire. Via a stiff wire, balloon aortic valvuloplasty under rapid pacing $(180 / \mathrm{min})$ was performed. After advancement of a 16-20 F femoral sheath, the Edwards Sapien bioprosthesis (balloon-expandable titanium frame containing bovine pericardial leaflets) or Medtronic Corevalve bioprosthesis (self-expandable nitinol frame containing porcine pericardial leaflets in supra-annular position) was deployed. Selection of the device size was based on previous aortic root assessment by TEE, CTA or angiography. After TAVI, LAA exclusion and septal closure procedures followed on. In all cases the first generation Amplatzer Cardiac Plug (ACP) was used. Similar to TAVI, LAA occlusion was performed in a 
Table 1

Individual case description

(1) 78-year-old man AS, CAD, AFib

(2) 84-year-old woman, AS, CAD, ASD, AFib

(3) 84-year-old woman, AS, CAD, PFO, AFib

(4) 88-year-old woman, AS, CAD, AFib

(5) 85-year-old woman, AS, AFib

(6) 83-year-old man, AS, CAD, AFib

(7) 79-year-old man, AS, CAD, AFib

(8) 80-year-old woman, AS, CAD, PFO, AFib

(9) 63-year-old man, AS, CAD, AFib

(10) 89-year-old woman, AS, CAD, AFib
Rationale: high risk of bleeding/avoidance of triple therapy

TAVI: Medtronic Corevalve $29 \mathrm{~mm}$

PCI: Promus $2.75 \times 23 \mathrm{~mm}$ (LCX), Xience $3.0 \times 12$ (LAD), SYNTAX score: 14

LAAO: Amplatzer Cardiac Plug $20 \mathrm{~mm}$

Rationale: high risk of bleeding/avoidance of triple therapy

TAVI: Medtronic Corevalve $26 \mathrm{~mm}$

PCl: Biomatrix 3.0×18 (LAD), SYNTAX score: 12

ASD closure: Amplatzer Septal Occluder $24 \mathrm{~mm}$

LAAO: Amplatzer Cardiac Plug $24 \mathrm{~mm}$

Rationale: high risk of bleeding/avoidance of triple therapy

TAVI: Edwards Sapien XT $26 \mathrm{~mm}$

PCl: Resolute 3.0×18 mm (RCA) LAAO: Amplatzer Cardiac Plug 22 mm, SYNTAX score: 6

PFO closure: Amplatzer PFO Occluder $25 \mathrm{~mm}$

Rationale: history of Gl-bleeding/avoidance of triple therapy

TAVI: Edwards Sapien XT 23 mm, SYNTAX score: 35

LAAO: Amplatzer Cardiac Plug $20 \mathrm{~mm}$

Rationale: history of Gl-bleeding/avoidance of triple therapy

TAVI: Edwards Sapien XT 26 mm, SYNTAX score: 0

LAAO: Amplatzer Cardiac Plug $28 \mathrm{~mm}$

Rationale: history of Gl bleeding/avoidance of triple therapy

TAVI: Medtronic Corevalve $31 \mathrm{~mm}$

PCI (prior to TAVI and LAAO): Xience Prime $\times 4$ (RCA, LAD), SYNTAX score: 12

LAAO: Amplatzer Cardiac Plug $20 \mathrm{~mm}$

Cerebral Protection with Claret

Rationale: high risk of bleeding/avoidance of triple therapy

TAVI: Medtronic Corevalve $29 \mathrm{~mm}$

PCI (prior to TAVI and LAAO): Orsiro $\times 2$ (LCX), SYNTAX score: 16

LAAO: Amplatzer Cardiac Plug $22 \mathrm{~mm}$

Rationale: high risk of bleeding/avoidance of triple therapy

TAVI: Medtronic Corevalve $26 \mathrm{~mm}$, SYNTAX score: 0

LAAO: Amplatzer Cardiac Plug $16 \mathrm{~mm}$

PFO closure: Amplatzer PFO Occluder $25 \mathrm{~mm}$

Rationale: history of Gl-bleeding/avoidance of triple therapy

TAVI: Edwards Sapien XT 23 mm, SYNTAX score: 24

LAAO: Amplatzer Cardiac Plug $22 \mathrm{~mm}$

Rationale: high risk of bleeding / avoidance of triple therapy

TAVI: Edwards Sapien XT $23 \mathrm{~mm}$

PCI: Orsiro $\times 2$ (LAD), SYNTAX score: 30

LAAO: Amplatzer Cardiac Plug $26 \mathrm{~mm}$

AFib, atrial fibrillation; AS, aortic valve stenosis; ASD, atrial septal defects; CAD, coronary artery disease; LAAO, left atrial appendage occlusion; LAD, left anterior descending coronary artery; LCX, left circumflex coronary artery; PCI, percutaneous coronary interventions; TAVI, transcatheter aortic valve implantation.

frugal manner without general anaesthesia or TEE guidance, that is, under fluoroscopy only: after accessing the left atrium through a trans-septal puncture or passage through a pre-existing PFO or ASD, the device size was selected based on biplane angiography of the LAA through the 9-13 F delivery sheath. After deployment, sustained tugging with the delivery cable tested ACP seating within the LAA and another biplane left atrial angiography was performed prior to the release. In case of unsatisfactory positioning or anchoring, the plug was recaptured and redeployed in a different angle or changed for a more suitable sized device. On the way back, a pre-existing PFO or ASD was closed by the same cable and delivery sheath using Amplatzer PFO or ASD occluders. After closure of the percutaneous arterial access and slight compression of the femoral vein, patients were posthydrated with normal saline according to the standard protocol and transferred to a cardiac intermediate care ward (see figures 1 and 2 for a representative course of action in case 2). Restart of oral anticoagulation was omitted. A dose of $75 \mathrm{mg}$ of clopidogrel daily for 3-6 months and $100 \mathrm{mg}$ of acetylsalicylic acid were prescribed indefinitely. For documentation of aortic bioprosthesis performance and exclusion of device displacement or pericardial effusion, transthoracic echocardiography was performed on day one after intervention and after 30 days. The patients were discharged on postprocedure days 3-7. 


\section{Table 2}

\begin{tabular}{llll}
\hline Baseline characteristics & TAVI matched cases $(\mathbf{n = 1 0 0 )}$ & Combined interventions $\mathbf{( n = 1 0 )}$ & $\mathbf{p}$ Value \\
\hline Age (years) & $83.5 \pm 5.8$ & $82.3 \pm 7.8$ & 0.67 \\
BMI $\left(\mathrm{kg} / \mathrm{m}^{2}\right.$ ) & $24.8 \pm 4.8$ & $26.1 \pm 4.0$ & 0.28 \\
CHADS ${ }_{2}$ score (points) & $2.6 \pm 0.8$ & $2.8 \pm 1.5$ & 0.84 \\
Creatinine clearance (mL/min) & $44.4 \pm 19$ & $41.8 \pm 13$ & 0.81 \\
Female gender & $59 / 100(59 \%)$ & $6 / 10(60 \%)$ & 1 \\
Coronary artery disease & $65 / 100(65 \%)$ & $9 / 10(90 \%)$ & 0.16 \\
Prior myocardial infarction & $14 / 100(14 \%)$ & $4 / 10(40 \%)$ & 0.23 \\
Prior CABG & $15 / 100(15 \%)$ & $3 / 10(30 \%)$ & 0.21 \\
Prior stroke & $12 / 100(12 \%)$ & $1 / 10(10 \%)$ & 1 \\
LV-EF $(\%)$ & $59 \pm 10$ & 0.12 \\
AVA (cm $\left.{ }^{2}\right)$ & $49 \pm 17$ & $0.6 \pm 0.2$ & 0.38 \\
Mean transvalvular aortic gradient & $0.5 \pm 0.2$ & $54 \pm 17$ & 0.055 \\
Logistic EURO score I $(\%)$ & $31 \pm 18$ & $22.3 \pm 11.1$ & 0.17 \\
Logistic EURO score II $(\%)$ & $11.3 \pm 8.1$ & $11.2 \pm 7.3$ & 0.90 \\
STS score (\%) & $10.5 \pm 5.7$ & $10.9 \pm 6.6$ & 0.98 \\
Atrial fibrillation & $37 / 100(37 \%)$ & $10 / 10(100 \%)$ & 0.0001 \\
\hline AVA
\end{tabular}

AVA, aortic valve area; BMI, body mass index; CABG, coronary artery bypass graft; CHADS, congestive heart failure, age, diabetes, stroke; LV-EF, left ventricular ejection fraction; TAVI, transcatheter aortic valve implantation.

\section{Matching and statistical analysis}

For every combined case, 10 controls were selected from the database according to the most fitting STS score. Since the STS score contains all relevant patient characteristics and has been shown to be very accurate in predicting a 30-day outcome also in TAVI patients, it was deemed appropriate for matching. Continuous variables are presented as mean $\pm \mathrm{SD}$ and were compared using the unpaired Mann-Whitney U test. Categorical data are expressed as frequency (percentages) and were compared with Fisher's exact test. All tests and CIs are two-sided, and an $\alpha$ level of 0.05 was chosen to determine the statistical significance of differences. Analyses were performed using GraphPad Prism 6 (http://www. graphpad.com).

\section{RESULTS}

\section{Baseline characteristics and matching}

Table 1 provides a brief description of each individual case and baseline characteristics are summarised in table 2. The rationale for LAA occlusion along with
TAVI ( 5 with CoreValve, 5 with Edwards Sapien XT) and PCI were high bleeding risk in six and prior major bleeding in four patients. In 3 of the 10 patients, PFO closure (2) and ASD closure (1) were performed in addition. Matching could be performed with an excellent agreement (mean difference in STS score between cases and control groups: $0.37 \pm 1.01$ ) .

\section{Periprocedural and 1-month follow-up}

Expectedly, procedure time, use of contrast and radiation was higher in the combined group when compared with the controls with TAVI only. Despite these drawbacks, no difference in the VARC endpoints was evident during the in-hospital period and after 30 days (see tables 3 and 4 ).

\section{Three-month follow-up}

Table 5 illustrates the 3-4 months clinical and echocardiographic follow-up data. No patient was lost to follow-up. All patients but one (sudden cardiac death 118 days after the index procedure) were alive without

\section{Table 3}

\begin{tabular}{lllr}
\hline Periprocedural outcomes & TAVI matched cases $(\mathbf{n = 1 0 0 )}$ & Combined interventions $(\mathbf{n = 1 0})$ & $\mathbf{p}$ Value \\
\hline Procedure time (min) & $83 \pm 40$ & $126 \pm 42$ & 0.0016 \\
Fluoroscopy time (min) & $22 \pm 12$ & $34 \pm 8$ & 0.0001 \\
Contrast dye (mL) & $250 \pm 105$ & $397 \pm 89$ & $<0.0001$ \\
Successful device implantation & $99 / 100(99 \%)$ & $10 / 10(100 \%)$ & 1 \\
VARC access site complication (all) & $26 / 100(26 \%)$ & $2 / 10(20 \%)$ & 1 \\
Need for femoral covered stent & $20 / 100(20 \%)$ & $1 / 10(10 \%)$ & 0.68 \\
VARC bleeding (all) & $45 / 100(45 \%)$ & $4 / 10(40 \%)$ & 1 \\
VARC kidney injury (all) & $17 / 100(17 \%)$ & $2 / 10(20 \%)$ & 0.68 \\
VARC kidney injury stage 3 & $4 / 100(4 \%)$ & $2 / 10(20 \%)$ & 0.09 \\
\hline TAVI, transcatheter aortic valve implantation; VARC, Valve Academic Research Consortium. &
\end{tabular}


Table 4

\begin{tabular}{lclc}
\hline 1-Month follow-up (VARC endpoints) & TAVI matched cases $(\mathbf{n = 1 0 0 )}$ & Combined interventions (n=10) & $\mathbf{p ~ V a l u e}$ \\
\hline Death & $11 / 100(11 \%)$ & $0 / 10(0 \%)$ & 0.59 \\
Cardiac death & $10 / 100(10 \%)$ & $0 / 10(0 \%)$ & 0.59 \\
Myocardial infarction & $0 / 100(0 \%)$ & $0 / 10(0 \%)$ & 1 \\
Stroke (all) & $4 / 100(4 \%)$ & $0 / 10(0 \%)$ & 1 \\
MACE & $14 / 100(14 \%)$ & $0 / 10(0 \%)$ & 0.36 \\
VARC combined safety endpoint & $32 / 100(32 \%)$ & $3 / 10(20 \%)$ & 1 \\
\hline
\end{tabular}

TAVI, transcatheter aortic valve implantation; VARC, Valve Academic Research Consortium.

events. Aortic bioprosthesis function was normal in all patients with no or mild paraprosthetic aortic regurgitation. No residual shunts or thrombi were seen after LAAO or PFO/ASD closure.

\section{DISCUSSION}

Surgical aortic valve replacement is associated with an unadjusted operative mortality of $3 \%$ and reaches $5 \%$ when combined with CABG. The surgical mortality rate

\section{Table 5}

\section{3-Month follow-up}

(1) 78-year-old man, AS, CAD, AFib

(2) 84-year-old woman, AS, CAD, ASD, AFib

(3) 84-year-old woman, AS, CAD, PFO, AFib

(4) 88-year-old woman, AS, CAD, AFib

(5) 85-year-old woman, AS, AFib

(6) 83-year-old man, AS, CAD, AFib

(7) 79-year-old man, AS, CAD, AFib

(8) 80-year-old woman, AS, CAD, PFO, AFib

(9) 63-year-old man, AS, CAD, AFib

(10) 89-year-old woman, AS, CAD, AFib
Status: free from embolic events

TAV: normal function, moderate AR

ACP: correct position; sufficient LAA exclusion, no shunt and no thrombus

Tx: ASA, clopidogrel and no anticoagulation

Status: free from embolic events

TAV: normal function, moderate AR

ACP: correct position; sufficient LAA exclusion, no shunt, no thrombus

Tx: ASA, clopidogrel, no anticoagulation

Status: free from embolic events

TEE denied

Tx: ASA, clopidogrel, no anticoagulation

Status: died from sudden cardiac death 118 days after Intervention TEE not performed

Status: free from embolic events TEE denied

Tx: clopidogrel, no anticoagulation

Status: free from embolic events

TAV: normal function, mild AR

ACP: correct position; sufficient LAA exclusion, no shunt, no thrombus

Tx: ASA, clopidogrel, no anticoagulation

Status: free from embolic events

TAV: normal function, mild AR

ACP: correct position; sufficient LAA exclusion, no shunt, no thrombus

Tx: ASA, clopidogrel, no anticoagulation

Status: free from embolic events

TAV: normal function, mild AR

PFO: correct position; no residual shunt, no thrombus

ACP: correct position; sufficient LAA exclusion, no shunt, no thrombus

Tx: ASA, clopidogrel, no anticoagulation

Status: free from embolic events

TAV: normal function, no AR

ACP: correct position; sufficient LAA exclusion, no shunt, no thrombus

Tx: ASA, clopidogrel, no anticoagulation

Status: free from embolic events

TAV: normal function, no AR

ACP: correct position; sufficient LAA exclusion, no shunt, no thrombus

Tx: ASA, clopidogrel, no anticoagulation 
rises exponentially in patients above 80 years. ${ }^{19}$ Rates of thromboembolic complications (related to atrial fibrillation and paradoxical embolism) as well as spontaneous and iatrogenic bleeding tendency increase with advancing age as reflected in contemporary risk stratification systems. Octogenarians are reluctant to seek medical care and physicians are hesitant to apply appropriate therapeutic strategies. With the introduction of various catheter-based percutaneous structural heart disease interventions, this hitherto neglected morbid population gains access to guideline-based medical care.

In our series, all patients had severe aortic stenosis (which was treated by TAVI) and eight of them had significant coronary artery disease (of whom six were treated with DES along with TAVI). Regarding the time point of treating concomitant $\mathrm{CAD}$, this should be treated at one time with the respective procedure of aortic valve replacement, irrespective of the approach selected by the heart team beforehand (ie, surgical revascularisation and SAVR or PCI and TAVI).

On top of that they had atrial fibrillation, which would have required chronic anticoagulation CHADS $_{2}$ score for all patients $>1$ ) in addition to dual antiplatelet therapy recommended for coronary stents for at least 3-6 months. Although newer data suggest safety and efficacy of a combination of clopidogrel and oral anticoagulation, many patients still receive triple oral antithrombotic therapy, which carries a significantly higher risk of bleeding than dual antiplatelet therapy ${ }^{20} 21$ while dual antiplatelet therapy alone is less effective than oral anticoagulation in preventing thromboembolic complications. ${ }^{22}$ LAA closure provides stroke prevention equal to that of warfarin without bleeding risk. ${ }^{11}$ Although the value of PFO/ASD closure as a primary prevention measure against paradoxical embolism is not clear, we performed this as the final step of the combined interventions among these patients because of the general ease of this intervention in the setting of LAA closure, with the appropriate gear already in place.

Compared with their matched counterparts receiving TAVI only, the combined intervention cases suffered from a higher burden of comorbidities and their procedures were longer and consumed more contrast dye. In spite of these disadvantages, the immediate and intermediate-term outcomes were not different between groups as judged by the VARC criteria. Alternatively to this single session approach a staged approach may reduce dye usage per session and hence transient kidney injury is occasionally encountered. However, this occurs at the expense of reduced patient comfort and compliance, which may lead to refraining from planned complementary interventions. Obviously, the power of the present study is too low to address the safety of increased contrast use. The combined procedures were all performed without general anaesthesia and without TEE guidance. Combining therapeutic measures becomes even more compelling if general anaesthesia and TEE guidance are deemed necessary.

\section{Limitations}

The present study has several limitations: first, the presented data reflect the experience of a high-volume tertiary care cardiology department. Second, due to the retrospective and observational character of the study, there was no prospective randomisation of cases, although the baseline STS score showed good agreement between the two groups after the performed matching process. Moreover, due to the manual matching a potential bias could have been introduced as compared with an automated process. Furthermore, the number of the reported combined cases and the respective event rates are low. Therefore, the issues of safety and net clinical benefit cannot be cleared definitively on the basis of the present study.

\section{Conclusions}

Transcatheter treatment of combined cardiac diseases is feasible even in a single session in high-volume centres with experienced operators. However, for definite proof of safety comparable to TAVI-only procedures, larger numbers of combined procedures or ideally, a controlled, prospective randomised study would be desirable.

Funding This research received no specific grant from any funding agency in the public, commercial or not-for-profit sectors.

Competing interests BM has received lecture fees from AGA Medical; AK is a proctor of AGA's LAA occlusion programme, SW and PW have received unrestricted grants from Medtronic and Edwards Lifesciences. FN, LB and AK are proctors for Edwards and Medtronic.

Provenance and peer review Not commissioned; externally peer reviewed.

Data sharing statement No additional data are available.

Open Access This is an Open Access article distributed in accordance with the Creative Commons Attribution Non Commercial (CC BY-NC 3.0) license, which permits others to distribute, remix, adapt, build upon this work noncommercially, and license their derivative works on different terms, provided the original work is properly cited and the use is non-commercial. See: http:// creativecommons.org/licenses/by-nc/3.0/

\section{REFERENCES}

1. Likosky DS, Sorensen MJ, Dacey LJ, et al. Northern New England Cardiovascular Disease Study Group. Long-term survival of the very elderly undergoing aortic valve surgery. Circulation 2009;120:S127-33.

2. Edwards FH, Peterson ED, Coombs LP, et al. Prediction of operative mortality after valve replacement surgery. J Am Coll Cardiol 2001;37:885-92.

3. Leon MB, Smith CR, Mack M, et al. PARTNER Trial Investigators. Transcatheter aortic-valve implantation for aortic stenosis in patients who cannot undergo surgery. N Engl J Med 2010;363:1597-607.

4. Stortecky S, Buellesfeld L, Wenaweser $P$, et al. Atrial fibrillation and aortic stenosis: impact on clinical outcomes among patients undergoing transcatheter aortic valve implantation. Circ Cardiovasc Interv 2013;6:77-84.

5. Pilgrim T, Kalesan B, Wenaweser $\mathrm{P}$, et al. Predictors of clinical outcomes in patients with severe aortic stenosis undergoing TAVI: a multistate analysis. Circ Cardiovasc Interv 2012;5:856-61.

6. Dewey TM, Brown DL, Herbert MA, et al. Effect of concomitant coronary artery disease on procedural and late outcomes of transcatheter aortic valve implantation. Ann Thorac Surg 2010;89:758-67.

7. Vahanian A, Baumgartner $\mathrm{H}$, Bax J, et al. Task Force on the Management of Valvular Heart Disease of the European Society of Cardiology; ESC Committee for Practice Guidelines. Eur Heart J 2007;28:230-68.

8. Conradi L, Seiffert M, Franzen O, et al. First experience with transcatheter aortic valve implantation and concomitant percutaneous coronary intervention. Clin Res Cardiol 2011;100:311-16. 
9. Wenaweser P, Pilgrim T, Guerios E, et al. Impact of coronary artery disease and percutaneous coronary intervention on outcomes in patients with severe aortic stenosis undergoing transcatheter aortic valve implantation. Eurolntervention 2011;7:541-8.

10. Pilgrim $\mathrm{T}$, Wenaweser $\mathrm{P}$, Windecker $\mathrm{S}$, et al. Comprehensive "one stop-shop" percutaneous cardiac intervention. Cardiovasc Med 2010;13:171-3.

11. Holmes DR, Reddy VY, Turi ZG, et al; PROTECT AF Investigators. Percutaneous closure of the left atrial appendage versus warfarin therapy for prevention of stroke in patients with atrial fibrillation: a randomised non-inferiority trial. Lancet 2009;374:534-42.

12. Reddy VY, Möbius-Winkler S, Miller MA, et al. Left atrial appendage closure with the Watchman Device in patients with a contraindication for oral anticoagulation: the ASAP Study (ASA Plavix Feasibility Study With Watchman Left Atrial Appendage Closure Technology) J Am Coll Cardiol 2013;61:2551-6.

13. Jones HR Jr, Caplan LR, Come PC, et al. Cerebral emboli of paradoxical origin. Ann Neurol 1983;13:314-19.

14. Bridges ND, Hellenbrand W, Latson L, et al. Transcatheter closure of patent foramen ovale after presumed paradoxical embolism. Circulation 1992;86:1902-8.

15. Chatterjee T, Aeschbacher B, Meier B. Non-surgical closure of secundum atrial septal defect and patent foramen ovale. Schweiz Med Wochenschr 1997;127:2054-60.
16. Wahl A, Praz F, Stinimann J, et al. Safety and feasibility of percutaneous closure of patent foramen ovale without intra-procedural echocardiography in 825 patients. Swiss Med Wkly 2008;138:567-72

17. Wahl $\mathrm{A}$, Jüni $\mathrm{P}$, Mono $\mathrm{M}$, et al. Long-term propensity score-matched comparison of percutaneous closure of patent foramen ovale with medical treatment after paradoxical embolism. Circulation 2012;125:803-12.

18. Leon MB, Piazza N, Nikolsky E, et al. Standardized endpoin definitions for transcatheter aortic valve implantation clinical trials: a consensus report from the Valve Academic Research Consortium. J Am Coll Cardiol 2011:57:253-69.

19. Astor BC, Kaczmarek RG, Hefflin B, et al. Mortality after aortic valve replacement: results from a nationally representative database. Ann Thorac Surg 2000;70:1939-45.

20. Mega J, Carreras ET. Antithrombotic therapy: triple therapy or triple threat? Hematology Am Soc Hematol Educ Program 2012;2012: 547-52.

21. Paikin JS, Wright DS, Crowther MA, et al. Triple antithrombotic therapy in patients with atrial fibrillation and coronary artery stents. Circulation 2010;121:2067-70.

22. Connolly S, Pogue J, Hart R, et al. Clopidogrel plus aspirin versus oral anticoagulation for atrial fibrillation in the Atrial fibrillation Clopidogrel Trial with Irbesartan for prevention of Vascular Events (ACTIVE W): a randomised controlled trial. Lancet 2006;367:1903-12. 